Faculdade de Ciências Econômicas UFRGS
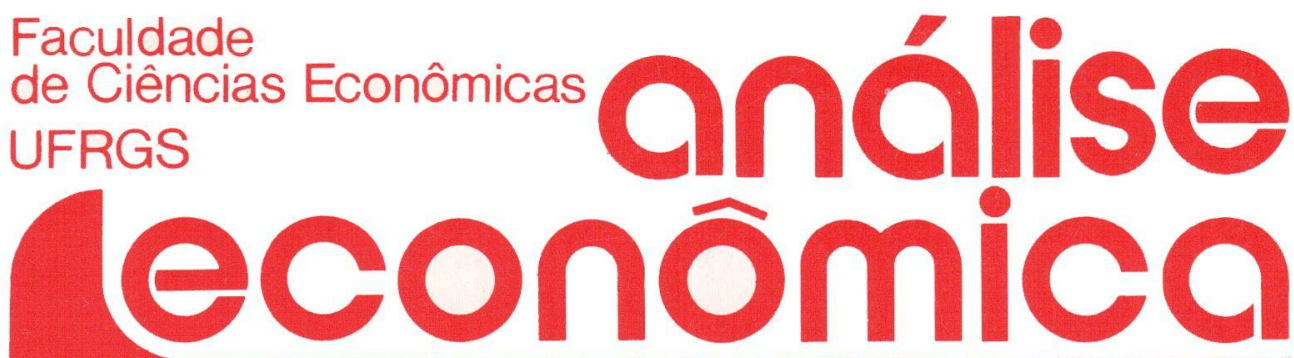

- A LINEAR MOdEL Of BALANCEd GROWTH Joanilio Rodolpho Teixeira Rodrigo Andrés de Souza Penaloza

- TEORIAS ESTRUTURALISTAS DA INFLAÇÃO

Roberto Camps Moraes

- PREÇOS EXTERNOS E EXPÓRTAÇÃO DE MANUFATURADOS Lauro Lobo Burle

- O DESENVOLVIMENTO SUECO Alfredo Marcolin Peringer

- DÉFICIT ENERGÉTICO Fabiano Augusto Nogueira Pinto

- RICARDO E O PROBLEMA SOCIAL Cezar Machado Mello

- UM SABER QUE NÃo SABE: INSTRUMENTO DE PREVISÃO Eleutério F.S. Prado

- SELEÇÃo dE PLANOS DE PRODUÇÃO PARA PEQUENOS PRODUTORES AGRICOLAS Juvir Luiz Mattuella

- PERSPECTIVAS da ECONOMIA do NORDESTE NA DÉCADA DE NOVENTA

Liana Maria da Frota Carleial

- CAIO PRADO JÚNIOR

Pedro Cezar Dutra Fonseca 
UNIVERSIDADE FEDERAL DO RIO GRANDE DO SUL Reitor. Prof. Tuiskon Dick

FACULDADE DE CIÊNCIAS ECONÔMICAS

Diretor: Prof. Walter Meucci Nique

CENTRO DE ESTUDOS E PESQUISAS ECONÔMICAS

Diretor: Reinaldo lgnácio Adams

DEPARTAMENTO DE CIÉNCIAS ECONÔMICAS

Chefe: Prof. Pedro Cezar Dutra Fonseca

CURSO DE PÓS-GRADUAÇÃO EM ECONOMIA

Coordenador: Prof. Nali de Jesus de Souza

CURSO DE PÓS-GRADUAÇĀO EM ECONOMIA RURAL

Coordenador. Prof. Atos Freitas Grawunder

CONSELHO EDITORIAL: Achyles Barcelos da Costa, Aray Miguel Feldens, Atos Freitas Grawunder, Carlos Augusto Crusius, Ernani Hickmann, João Rogério Sanson, Juvir Luiz Mattuella, Maria Imilda da Costa e Silva, Nali de Jesus de Souza, Nuno Renan Lopes de Figueiredo Pinto, Otília Beatriz Kroeff Carrion, Otto Guilherme Konzen, Paulo Alexandre Spohr, Pedro Cezar Dutra Fonseca, Reinaldo Ignacio Adams, Roberto Camps Moraes, Valter José Stülp, Yeda Rorato Crusius, David Garlow (Wharton Econometrics Forecasts Association, E.U.A.), Edgar Augusto Lanzer (UFSC), Eleutério F.S. Prado (USP), Fernando Holanda Barbosa (FGV/RJ), Gustavo Franco (PUC/RJ), Joaquim Pinto de Andrade (UnB), Juan H. Moldau (USP), Werner Baer (Univ. de Illinois, E.U.A.).

COMISSĀO EDITORIAL: Atos Freitas Grawunder, Pedro Cezar Dutra Fonseca, Reinaldo Ignacio Adams e Roberto Camps Moraes.

EDITOR: Nali de Jesus de Souza

SECRETARIA: Maria Ivone de Mello (normalização), Vanete Ricacheski (revisão de textos), Zélide Bregalda (Secretária).

FUNDADOR: Prof. Antônio Carlos Santos Rosa

Os materiais publicados na revista Análise Econômica são de exclusiva responsabilidade dos autores. É permitida a reprodução total ou parcial dos trabalhos, desde que seja citada a fonte.

Aceita-se permuta com revistas congêneres. Aceitam-se, também, livros para divulgação, elaboração de resenhas ou recensōes.

Toda correspondência, material para publicação, assinaturas e permutas devem ser dirigidos ao seguinte destinatário:

PROF. NALI DE JESUS DE SOUZA

Revista Análise Econômica

Av. João Pessoa, 52

90.040 - PORTO ALEGRE (RS), BRASIL

Telefone: (0512) 25-58-44 ramal 33

Fax: (0512) 25-5253 


\title{
PERSPECTIVAS DA ECONOMIA DO NORDESTE NA DÉCADA DE NOVENTA*
}

\author{
Liana Maria da Frota Carleial ${ }^{* \star}$
}

\section{SINOPSE}

A questảo regional nordestina sempre esteve colocada para o Estado e, dificilmente, perderá, nos próximos anos, essa vinculação. A população rural do Nordeste deverá passar de $45 \%$ do total da população trabaIhadora do Pals (1987) para $56 \%$ no fim da década de noventa. A queståo agråria tem, pois, um peso importante na questão regional. Novos investimentos de infra-estrutura e a ação no sentido de complementação do parque produtivo local, a fim de internalizar na Região os efeitos positivos do crescimento, não podem ficar dissociados das questões agricòla e agrảria.

Discutir perspectivas da economia nordestina na próxima década se constitui num esforço que encerra muitas dificuldades por conta da gravidade da crise que está e esteve mergulhada a década de oitenta, principalmente nos paises endividados. Esta década tem sido de profundas alterações em nível mundial no que se refere à reorganização dos mercados, aos padrões tecnológicos, ao reordenamento da relação capital/trabalho, sendo que o Brasil tem estado praticamente fora e alijado dessas alterações.

Aqui, a dificuldade de saída da crise e o aprofundamento dos seus endividamentos, principalmente o interno, têm colocado restrições sérias a qualquer análise de perspectiva o que não invalida, evidentemente, 0 traçado de cenários alternativos quanto à superação destas restrições. Dadas as peculiaridades da economia brasileira, no cerne da questão do

* Texto apresentado no Painel "Perspectivas da Economia do Nordeste na Década de Noventa" no XVII Encontro Nacional da ANPEC, no dia 05/12/89, em Fortaleza, Ce.

** Professora do Curso de Mestrado em Economia - CAEN, da UFC.

\begin{tabular}{|l|l|l|l|l|}
\hline ANÁLISE ECONO̊MICA & ANO 8 & NN 14 & NOVEMBRO/90 & p.141.150 \\
\hline
\end{tabular}


seu endividamento encontra-se o Estado.

$\mathrm{Na}$ realidade, pensar o futuro das economias regionais é extremamente audacioso diante das incertezas que estão presentes para a economia brasileira como um todo. Neste contexto, pensar as perspectivas da economia nordestina pode parecer uma ilusão. Porém, o quadro politico que se vive no momento é extremamente motivador no que se refere, pelo menos, a uma real possibilidade de se discutir as perspectivas da nossa economia. Por esta razão optamos por organizar nossa análise na direção de destacar alguns pontos no pressuposto de que às regiōes reste alguma possibilidade de alterar seus entraves e superar seus conflitos, pontos esses retirados da nossa compreensão do que aconteceu no Nordeste nos últimos anos.

Colocado esse preâmbulo, é interessante evidenciar a pertinência da questão regional e sua permanência no Brasil de hoje.

Vive-se um momento de total abandono da questão regional, comportamento ancorado no desempenho da economia brasileira e da nordestina dos últimos 30 anos e na proposta de integração da economia brasileira, de seus mercados, inclusive o de trabalho.

A constatação do comportamento da economia nordestina pósSudene é, na realidade, sem maiores discussōes, o elemento hoje utilizado para a sustentação da proposta de integração da economia nordestina à economia nacional e, quem sabe, até mesmo a sustentação da proposta de eliminação da questão regional.

A questão Regional no NE, como é sabido, surge desde o início como uma questão colocada para o Estado. Desde o século passado até os dias de hoje, esse aspecto não pode ser descuidado por razōes histórico-estruturais do desenvolvimento brasileiro e do processo de diferenciação econômico, social e político que se instala no território brasileiro e na conformação de suas regiões. Em poucos momentos da história nordestina aparece uma proposta de entendimento da Região que incorpore vontades populares. A grande exceção a esse comportamento foi o momento que antecedeu à criação da Sudene que redundou no GTDN e, posteriormente, no surgimento daquela instituição.

Mesmo assim, a natureza da ação do Estado na Região e o comportamento de suas elites permitiram o que Oliveira (1987) expressa na figura de que "a criatura (o sistema de incentivos) engole o criador" e, na realidade, o que se tem a partir daí, mais claramente, é a prática de um regionalismo, que se estabelece com uma linguagem única: a Região é tomada pelo seu povo e suas elites como seus representantes. 
Eliminam-se, em nivel do aparente, as diferenças e os conflitos intra-regionais, exageram-se os conflitos inter-regionais e o Nordeste e sua pobreza são utilizados como meios de enriquecimento de poucos.

Reçentemente, em nivel nacional, a crítica ao regionalismo nordestino tem aumentado assustadoramente na esteira do diagnóstico oficial e falacioso de que a causa do déficit público é determinada, primordialmente, pelos gastos com funcionários públicos e incentivos fiscais regionais. Uma pequena incursão ao orçamento da União para 1990 pode ajudar a revelar a magnitude dos recursos destinados à rolagem da dívida interna. Por outro lado, concorre para esta crítica a desinstrumentalização das instituições regionais para esclarecer com firmeza os resultados da utilização dos recursos públicos, permitindo o vazio e engrossando a voz dos discordantes. Na realidade, o discurso do "regionalismo espúrio" tem gerado um afastamento dos que militam nesta área na direção de aceitarem, com alguma placidez, a sua impropriedade.

Alguns pontos, porém, merecem destaque. Mesmo na esteira da proposta de integração da economia brasileira e da homogeneização dos seus espaços, foi possivel imprimir à Constituição de 88 um cunho regionalista pela obrigatoriedade dos recursos regionais especificos, mesmo que, até agora, não tenham se viabilizado integralmente. A nosso ver, é diante de todo esse quadro que se encaixa uma campanha presidencial na qual muitò pouco se tratou da questão regional. Na realidade, identifica-se que o regionalismo, tal como foi usado, serviu de instrumento para as elites se apropriarem e dirigirem o Estado do Nordeste, na direção de seus interesses.

Vive-se hoje, então, o temor de que se reedite o regionalismo e, com ele, o discurso e a prática das elites. Porém, torna-se cada vez mais urgente a conformação de um projeto regional que incorpore vivamente as necessidades do povo nordestino. Tem-se, no momento, uma possibilidade real de alteração dos atores que colocaram, historicamente, as questóes para o Estado. Essa parece ser a questão crucial na conformação das perspectivas da economia nordestina na próxima década.

É evidente que $o$ avanço considerável que as interpretações sobre - NE tiveram na fase pós-Sudene foi entender a formação de uma economia nacional, comandada pelas alteraçōes na divisão inter-regional do trabalho com base fundamentalmente no processo de industrialização. Esse é o suposto que inviabiliza as antiquadas análises regionais autonomizadas e pressupõe, necessariamente, as perspectivas de mudanças regionais presas ao encaminhamento de resolução dos proble- 
mas nacionais e aos rebatimentos internos das alteraçōes no padrão da divisão internacional do trabalho.

É evidente também que vive-se um processo de integração da economia nacional no sentido de que sua estrutura produtiva está distribuída em várias partes do território nacional. Por outro lado, só o reconhecimento da inserção regional na matriz produtiva nacional é insuficiente para orientar a discussão. É necessário deixar clara a natureza dessa integração e apontar as especificidades do Nordeste.

O componente mais forte dessa integração é a inexistência de barreiras comerciais e de transporte (característico das economias regionais) o que estabelece uma igualação nos padrões de consumo, ou seja, a integração é fundamentalmente de padrões de consumo. Concretamente, o Nordeste continua se colocando primordialmente como um espaço de realização.

A integração de natureza produtiva é ainda acanhada. $O$ desenvolvimento industrial do Nordeste, como é sabido, se encarregou de implantar um setor de bens intermediários ou insumos industriais e de modernizar o setor de bens de consumo não duráveis (Araújo, 1984). Esta tendência se manteve na década de oitenta uma vez que, no período 01.01 .80 a 30.06 .89 , do total dos investimentos regionais, $83,05 \%$ estiveram concentrados no setor de bens intermediários. Adicionalmente, do total dos recursos do FINOR, $71,19 \%$ se destinaram a esse setor produtivo.

Concretamente, a participação do produto industrial nordestino em 1970 era de 7,01\% do Produto Industrial Brasileiro, em 1975, 7,49\% e, em 1980 , atinge $9,49 \%$. Tudo isto foi feito sem contar com participação importante do capital regional e concentrado espacialmente. Quando se fala do dinamismo da indústria nordestina fala-se primordialmente do Pólo Petroquímico de Camaçari. Por exemplo, a responsabilidade do aumento de dois pontos percentuais da produção nordestina na produção da indústria nacional entre 75 e 80 é devida ao estado da Bahia (Carleial et alii, 1989, p.129). Adicionalmente, no ano de 1988, de acordo com algumas estimativas, o crescimento industrial do estado da Bahia foi da ordem de $13 \%$, enquanto a Regiāo sofria uma queda da ordem de $7 \%$ (Santos Filho, 1989, p.195).

No quadro rural, a situação não se alterou, tendo sido mantido o perfil fundiário e os programas governamentais foram pontuais, alterando partes para não mexer no todo (inclusive quanto ao combate às secas). 
Pode-se afirmar, então, que a integração produtiva é pontual (tanto em nivel urbano como rural) e dependente, o que decorre primordialmente da natureza dos ramos industriais aqui instalados.

A natureza dessa integração pode ser ilustrada através de algumas evidências:

- O Nordeste urbanizou-se, mas ainda é o espaço territorial brasileiro onde esse processo é lento;

- No espaço intra-regional identificam-se manchas de franca expansão como o oeste da Bahia, o sul do Piauí, o sudoeste do Maranhão (agricultura e pecuária) e em algumas capitais por conta da indústria, ao mesmo tempo em que grande parte da Região está estagnada e sem perspectivas.

É nos espaços em expansão que a ligação se faz mais em nivel nacional com as economias do Centro-Sul e do Centro-Oeste. Logo, identificam-se espaços atrelados à dinâmica nacional, em geral as metrópoles nordestinas, e espaços cada vez mais distantes do movimento à escala nacional. A questão imediata é que essa parcela da população já integrada se distancia muito dos não integrados e não há perspectiva de que essas parcelas marginalizadas venham a se integrar. Mais grave ainda parece ser a inviabilidade de tirar maior proveito para a Região, internamente, destes espaços em expansão.

A natureza dessa integração produtiva fica revelada ainda melhor na conformação do mercado de trabalho regional, desmistificando um pouco a tranqüilidade conferida pelos indicadores de crescimento econômico regional. Em 1987 no setor urbano, o Nordeste detinha 15,13\% dos trabalhadores com carteira assinada do pais. Já no setor rural, o NE detinha quase metade dos trabalhadores agrícolas e apenas $23,85 \%$ dos que detêm carteira assinada, $51,69 \%$ dos conta-própria e $43,75 \%$ dos sem carteira. Em termos de tamanho do mercado de trabalho, o NE equivale às regiões Sul e Sudeste juntas, sendo que estão nestas duas regiōes $70 \%$ dos trabalhadores que possuem carteira assinada. Quanto à remuneração dos trabalhadores, reproduzem-se as diferenças. Em 1988, 73\% ganhavam até 2 salários mínimos (Carleial, 1989).

Do que aqui foi exposto, pode ser dito que todo esse processo de integração redundou no aprofundamento das diferenças entre as populaçōes residentes no NE e a de outras regiōes no que se refere ao acesso a emprego, renda, serviços de infra-estrutura social e econômica e ainda o acirramento da concentração de renda e dos conflitos intra-regionais, em partes decorrentes da privatização do Estado. Do ponto de 
vista social, é bom salientar que, na virada do século, estarão mais distantes os diferenciais de mortalidade infantil e de esperança de vida ao nascer dos nordestinos em relação aos habitantes das regiōes mais desenvolvidas, de acordo com Camarano (1989).

Mesmo diante dos números que demonstram o dinamismo regional retratado no crescimento do produto regional e até de mornentos nos quais a Região cresce mais do que o centro hegemônico do pais, a permanência da pobreza, da desigualdade e da fragilidade de sua estrutura produtiva permitem algumas ponderações.

A primeira delas é questionar as interpretações otimistas quanto a esse desempenho, que, nem mesmo, levam em conta que diferentes taxas de crescimento correspondem a diferentes posicionamentos temporais no ciclo econômico de caráter nacional em decorrência das diferentes estruturas produtivas. $O$ crescimento que ocorreu na região muitas vezes se atribui como indicador da ausência de sentido com preocupações regionais. O que conta é a ótica do nacional. Sendo assim, é suficiente que a economia brasileira vá bem para que a região também o vá. Esse tipo de interpretação exagera na crença da integração produtiva regional e atropela as especificidades da economia que se tem neste pedaço do pais, ou seja, não Ihes confere validade. Na esteira desta interpretação, sobraria, ao Nordeste, as ações e medidas de combate à pobreza numa visão de Política Social reducionista e, quem sabe, benefícios de uma redistribuição de renda através de acesso a educação, saúde, transporte, etc.

$\dot{E}$ exatamente neste aspecto que pretendemos discordar e advogar a necessidade de um projeto próprio. E evidente que a integração existe, mas é essencialmente de padrões de consumo, sendo necessário que se processe uma ampliação desta integração em nível produtivo. Neste sentido, admitimos que é fundamental compreender e incorporar a natureza e a lógica do possivel desenvolvimento nacional, mas, também, é essencial buscar um projeto que não só incorpore outras áreas da Região à dinâmica nacional, bem como internalize no espaço territorial nordestino os efeitos deste crescimento e ainda incorpore as populaçōes marginalizadas do Nordeste.

Concretamente, pretendemos defender a necessidade de uma lógica distinta daquela que é simplesmente imposta pelo livre jogo de mercado, pelas hegemonias econômicas e a lógica do nacional. Contrariamente, afirmamos a natureza não só econômica, mas também sóciopolítica da questão regional. 
Essa é, a nosso juízo, a perspectiva da qual se precisa ver a economia do Nordeste na próxima década. A elaboração de um projeto regional que incorpore as vontades populares, destacando os entraves internos e não os externos ao desenvolvimento da região e a recolocação do regionalismo, não como utopia, nem como discurso das elites, mas sim como uma perspectiva imediata e concreta a partir da conformaçãó de suas estruturas econômicas e da mudança próxima que, muito provavelmente, ocorrerá no quadro político nacional.

A questão básica para nós é recuperar a possibilidade da Região se integrar mais efetivamente na matriz produtiva nacional e de superar internamente entraves a esse maior movimento de expansão à escala nacional, como a permanência de sua estrutura agrária e o caráter de sua indústria. Na realidade, a trajetória da expansão recente da indústria brasileira estabelece um corredor de conexão que vai de São Paulo ao Rio Grande do Sul e a Minas Gerais, deixando de fora a maior parte da região Nordeste.

A pretensão do crescimento do Nordeste com ganhos sociais, entendidos como ampliação de emprego e renda, exige a complementação da estrutura industrial nordestina. Por exemplo: o Ceará possui um pólo importante de confecções o qual deve importar aproximadamente $90 \%$ das matérias-primas e acessórios. É fundamental que se instalem aqui empresas que satisfăçam a demanda desse conjunto de empresas. Como conseqüência, além da criação de empregos e ampliação do mercado interno através do pagamento de salários, teremos a redução da sangria de recursos imposto pelas compras necessárias (importações) feitas às empresas fora da Região e que geram emprego e renda por lá.

Esta ação imporá a ampliação da integração produtiva do Nordeste na matriz industrial brasileira e da integração produtiva intra-regional bem ao contrário dos efeitos da Zona de Processamento de Exportação, que integra para fora e, assim, é uma antipolítica de desenvolvimento regional.

Vários exemplos poderiam se seguir para evidenciar a necessidade de complementação do parque industrial nordestino na direção de internalizar, na Região, os efeitos positivos do crescimento. Nesse sentido, propomos que, para essas empresas complementares, sejam mantidos os incentivos governamentais.

Destacamos ainda que essas empresas deveriam se instalar respeitando o mercado nacional no que se refere à tecnologia, "designs", e 
eficiência, mesmo porque elas terão que ter em mente conquistar esse mercado.

Um outro aspecto que merece a maior atenção decorre do fato de que, em 1987, o Nordeste detinha aproximadamente $45 \%$ de sua população trabalhadora ocupada na área rural do País e, na virada do século, essa participação deverá passar para 56\%. Assim, o Nordeste será o espaço da ruralização, no Brasil, segundo Camarano (1989). Considerando que é muito pouco provável que se continue sempre "resolvendo" os conflitos rurais no Nordeste, como se tem feito historicamente, assassinando seus lideres, é inadiável o enfrentamento da questão agrária nordestina. Vários aspectos despontam aqui. A questão agrária no Nordeste é específica: a modernização é pontual, há permanência e recriação de formas de relações de trabalho que prendem o trabalhador à terra, a concentração de terras permanece, ampliando assim a vulnerabilidade das populações atingidas pelas secas. E o mais grave: a produção de alimentos é cada vez menor.

Aqui vamos considerar outra questão essencial: a democratização e, portanto, a desprivatização do Estado. Propor questōes desta ordem, como as apresentadas anteriormente, é reacreditar na possibilidade de um Planejamento Regional, desta vez democrático, o que requer a possibilidade de Planejamento a Longo Prazo no Brasil e a redefinição dos papéis das instituições regionais de planejamento. Essa talvez seja a questão mais delicada e de dificil equacionamento, devido ao longo periodo da prática autoritária da tomada de decisões e do "encastelamento" dos resultados e avaliações. Por outro lado, neste quadro, refiro-me não só à Sudene e ao $\mathrm{BNB}$, mas também ao conjunto das estatais que atuam na Região.

Na realidade, é difícil propor um Planejamento Regional quando atuam na Região estatais de grande porte que não prestam conta a quaisquer organismos regionais nem quanto à sua atuação, nem quanto às suas ligações com as empresas privadas. Qual o poder que exerceu durante os últimos anos a Sudene sobre as empresas estatais que trabalham na Região? É possivel imaginar uma ação planejada num determinado espaço sem que esteja incluido neste plano as atividades destas empresas e, por conseguinte, a dimensão setorial? A quem cabe gerir o território: as empresas estatais da União ou as instituições de Planejamento Regional?

$\mathrm{Na}$ realidade, é necessário que aos organismos regionais seja entregue a formulação do Planejamento Regional e a compatibilização 
com a ação das estatais na Região.

Finalmente, não se pode deixar de mencionar os urgentes investimentos em infra-estrutura econômica (onde se destaca claramente a necessidade de expansão da geração de energia elétrica) e social (habitação, educação, saúde, transporte, saneamento, etc.) numa ação clara de distribuição de renda.

Relacionar necessidades sem arrolar fontes de financiamento cada vez mais instala desconfiança entre economistas, num país em crise. De concreto temos os recursos constitucionais que, como se sabe, exigem aplicação produtiva, mas ainda não conhecemos o plano de aplicação desenvolvido pelo BNB e submetido à Sudene. Quanto aos recursos para a infra-estrutura só mesmo a inversão das prioridades e uma política clara de redistribuição de renda e poder neste país seriam capazes de mobilizá-los.

Quer me parecer que a significativa votação que o candidato Luis Inácio Lula da Silva obteve no NE, principalmente nas áreas urbanas, pode ser um indicador de que haja uma forte crença de que só uma proposta democrática no sentido da explicitação das diferenças e da incorporação das vontades populares seja capaż de dar ao povo brasileiro a possibilidade de não se sentir "por fora" dos rumos a serem dados à economia nacional e regional.

\section{BIBLIOGRAFIA}

ARAÚJO, T.B. Industrialização do Nordeste. Intenções e Resultados, In: MARANHĀO, S. A Questão Nordeste. Estudos Sobre Formação Histórica, Desenvolvimento e Processos Políticos e Ideológicos. Rio de Janeiro, Paz e Terra, 1984.

CAMARANO, Ana A. Painel Nordeste 2000. In: REUNIĀO DA SOCIEDADE BRASILEIRA PARA O PROGRESSO DA CIÊNCIA - SBPC, Fortaleza, ABEP, jul. 1989.

CARLEIAL, Liana M. Observações Sobre a Concepção de Integração do Mercado de Trabalho no Brasil. Fortaleza, CAEN/UFC, 1989. (Texto para Discussão n. 78).

CARLEIAL, Liana M. \& NABUCO, Maria R. (orgs.) Transformações na Divisão Inter-Regional do Trabalho no Brasil. Fortaleza/Belo Horizonte, ANPEC/CAEN/CEDEPLAR, 1989.

OLIVEIRA, Francisco. Sudene: Volta a Planejar? Espaço e Debates, v.1, n.20, 1987. 
SANTOS FILHO, M. Notas Sobre as Redefinições do Sistema Produtivo e Transformações Regionais. In: CARLEIAL, Liana M. \& NABUCO, Maria R. Op. Cit., 1989.

\section{ABSTRACT \\ SOMES NOTES ON PERSPECTIVES FOR THE ECONOMY OF THE NORTHEAST IN THE NINETIES}

The northeastern regional question has always been put to the State and will hardly loose, in the next years, this link. The rural northeastern people should grow from $45 \%$ of the total rural working people of the country, in 1987 , to $56 \%$ at the end of the nineties. The agricultural question has then a great importance in the regional question. New investments on social overhead and an action to supplement the local plants so as to internalize in the region the positive effects of growth, can not be dissociated from the agricultural and agrarian questions. 